\title{
HER2 in situ hybridization in breast cancer: clinical implications of polysomy 17 and genetic heterogeneity
}

Wedad M Hanna ${ }^{1}$, Josef Rüschoff ${ }^{2}$, Michael Bilous ${ }^{3}$, Renata A Coudry ${ }^{4}$, Mitch Dowsett ${ }^{5}$, Robert Y Osamura ${ }^{6}$, Frédérique Penault-Llorca ${ }^{7}$, Marc van de Vijver ${ }^{8}$ and Giuseppe Viale $^{9}$

${ }^{1}$ Department of Laboratory Medicine and Pathobiology, University of Toronto, Toronto, ON, Canada;

${ }^{2}$ Institute of Pathology Nordhessen, Kassel, Germany; ${ }^{3}$ Healthscope Pathology, Norwest Private Hospital, Bella Vista, NSW, Australia; ${ }^{4}$ State of São Paulo Cancer Institute (ICESP), São Paulo, Brazil; ${ }^{5}$ Royal Marsden Hospital, London, UK; ${ }^{6}$ International University of Health and Welfare (IUHW), Center for Diagnostic

Pathology, IUHW Mita Hospital, Tokyo, Japan; ${ }^{7}$ Centre Jean Perrin and University of Auvergne, EA 4233, Clermont-Ferrand, France; ${ }^{8}$ The Academic Medical Center (AMC), The University of Amsterdam, Amsterdam, The Netherlands and ${ }^{9}$ University of Milan and European Institute of Oncology, Milan, Italy

Trastuzumab-containing therapy is a standard of care for patients with HER2 + breast cancer. HER2 status is routinely assigned using in situ hybridization to assess HER2 gene amplification, but interpretation of in situ hybridization results may be challenging in tumors with chromosome 17 polysomy or intratumoral genetic heterogeneity. Apparent chromosome 17 polysomy, defined by increased chromosome enumeration probe 17 (CEP17) signal number, is a common genetic aberration in breast cancer and represents an alternative mechanism for increasing HER2 copy number. Some studies have linked elevated CEP17 count ('polysomy') with adverse clinicopathologic features and HER2 overexpression, although there are numerous discrepancies in the literature. There is evidence that elevated CEP17 ('polysomy') count might account for trastuzumab response in tumors with normal HER2:CEP17 ratios. Nonetheless, recent studies establish that apparent 'polysomy' (CEP17 increase) is usually related to focal pericentromeric gains rather than true polysomy. Assigning HER2 status may also be complex where multiple cell subclones with distinct HER2 amplification characteristics coexist within the same tumor. Such genetic heterogeneity affects up to $40 \%$ of breast cancers when assessed according to a College of American Pathologists guideline, although other definitions have been proposed. Recent data have associated heterogeneity with unfavorable clinicopathologic variables and poor prognosis. Genetically heterogeneous tumors harboring HER2-amplified subclones have the potential to benefit from trastuzumab, but this has yet to be evaluated in clinical studies. In this review, we discuss the implications of apparent polysomy 17 and genetic heterogeneity for assigning HER2 status in clinical practice. Among our recommendations, we support the use of mean HER2 copy number rather than HER2:CEP17 ratio to define HER2 positivity in cases where coamplification of the centromere might mask HER2 amplification. We also highlight a need to harmonize in situ hybridization scoring methodology to support accurate HER2 status determination, particularly where there is evidence of heterogeneity.

Modern Pathology (2014) 27, 4-18; doi:10.1038/modpathol.2013.103; published online 28 June 2013

Keywords: breast cancer; chromosome 17; genetic heterogeneity; HER2 testing; in situ hybridization; polysomy

HER2 is a member of the human epidermal growth factor receptor family encoded by a gene located on the long arm of chromosome 17 (17q12-21.32). ${ }^{1}$

Correspondence: Dr W Hanna, MD, FRCPC, Anatomic Pathology, Sunnybrook Health Sciences Centre, 2075 Bayview Avenue, Room E4 32, Toronto, ON M4N 3M5, Canada.

E-mail: wedad.hanna@sunnybrook.ca

Received 9 January 2013; revised 5 April 2013; accepted 11 April 2013; published online 28 June 2013
Around $20 \%$ of breast cancers are reported to overexpress HER2 and/or exhibit amplification of the ERBB2 gene (referred to here as HER2 in line with common practice), ${ }^{2}$ although our experience suggests that, in practice, the rate of HER2 positivity is closer to $15 \%$. HER2 positivity is established as a poor prognostic marker associated with more aggressive disease and decreased survival. ${ }^{3-5}$

Trastuzumab, a monoclonal antibody targeting HER2, has demonstrated efficacy as a single agent 
or in combination with chemotherapy in patients with HER2-overexpressing primary and metastatic breast cancer. ${ }^{6-12}$ Consequently, treatments that include trastuzumab have become the standard of care for patients with HER2 + early or metastatic disease. ${ }^{13-15}$ As the clinical benefits of trastuzumab are highly associated with HER2 positivity, ${ }^{7-12}$ HER2 testing is recommended at diagnosis of all breast cancers to determine potential eligibility for trastuzumab therapy. ${ }^{16}$

Two diagnostic techniques are currently approved for assigning HER2 status in clinical practice: immunohistochemistry (IHC) and in situ hybridization (ISH). Whereas IHC uses an antibody to evaluate HER2 protein expression, ISH determines the number of HER2 copies using a DNA probe coupled to a fluorescent, chromogenic, or silver detection system (ie, FISH, CISH, or SISH), or a combination of CISH and SISH systems (bright-field double ISH (BDISH) or dual-hapten, dual-color ISH (DDISH)). ISH is conducted using a single probe to enumerate HER2 copies per nucleus only or as a dual-probe technique where hybridization of a chromosome 17 centromere probe (chromosome enumeration probe 17, CEP17) allows determination of the HER2:CEP17 ratio. The two-probe approach may be performed as a dual-color technique, with cohybridization of the two probes on the same slide, or as a monochrome assay where each probe is used on sequential slides. The HER2:CEP17 ratio is sometimes regarded as a better reflection of HER2 amplification status than mean HER2 copy number, as the latter is also dependent on the mitotic index of the tumor, section thickness, nuclear truncation effects, and abnormal chromosome copy number (aneusomy). ${ }^{17}$

US Food and Drug Administration-approved package inserts for HER2 tests originally defined HER2 positivity according to IHC scores of $2+$ (weakly positive) or $3+$ (positive), mean HER2 copies per nucleus $>4$ or HER2:CEP17 ratio $\geq 2.0$ depending on the type of assay used (Table 1). Patients with IHC $2+$ /ISH-negative tumors are not eligible for trastuzumab treatment to date. However, 2007 guidelines from the American Society of Clinical Oncology and College of American Pathologists raised the thresholds for HER2 positivity and introduced equivocal ranges for IHC and FISH results. $^{2}$ The guidelines state that an equivocal result should prompt additional testing, but the authors have since emphasized that trastuzumab should not be withheld from patients with equivocal scores that would be considered positive under the original Food and Drug Administration cutoffs. ${ }^{18}$ American Society of Clinical Oncology and College of American Pathologists recommended either IHC or FISH as an initial assay, but others prefer FISH as the primary test, arguing that the accuracy of IHC testing is limited by technical considerations and the inherent subjectivity of scoring. ${ }^{19}$

Although the American Society of Clinical Oncology and College of American Pathologists algorithms

Table 1 Food and Drug Administration ${ }^{89}$ and American Society of Clinical Oncology/College of American Pathologists ${ }^{2}$ cutoffs for HER2 status determination by IHC or FISH

\begin{tabular}{|c|c|c|c|c|c|c|}
\hline & \multicolumn{2}{|c|}{$I H C$} & \multicolumn{4}{|c|}{ FISH } \\
\hline & \multirow[t]{2}{*}{$F D A$} & \multirow[t]{2}{*}{ ASCO/CAP } & \multicolumn{2}{|c|}{$\begin{array}{l}\text { HER2 copies, } \\
\text { average per nucleus }\end{array}$} & \multicolumn{2}{|c|}{ HER2:CEP17 ratio } \\
\hline & & & $F D A$ & ASCO/CAP & $F D A$ & ASCO/CAP \\
\hline Negative & $0-1+$ & $0-1+$ & $\leq 4.0$ & $<4.0$ & $<2.0$ & $<1.8$ \\
\hline Equivocal & - & $\begin{array}{c}2+\text { (nonuniform or weak } \\
\text { complete membrane } \\
\text { staining in } \geq 10 \% \text { tumor } \\
\text { cells, or intense, complete } \\
\text { membrane staining in } \\
\leq 30 \% \text { invasive tumor } \\
\text { cells) }\end{array}$ & - & $4.0-6.0$ & - & $1.8-2.2$ \\
\hline Positive & $\begin{array}{c}2+\text { (weak-to-moderate } \\
\text { complete membrane } \\
\text { staining in }>10 \% \text { of } \\
\text { tumor cells), } 3+\text { (strong } \\
\text { complete membrane } \\
\text { staining in }>10 \% \text { of } \\
\text { tumor cells). Patients with } \\
\text { IHC } 2+/ \text { ISH }- \text { tumors are } \\
\text { not eligible for } \\
\text { trastuzumab treatment to } \\
\text { date }\end{array}$ & $\begin{array}{c}3+\text { (uniform intense } \\
\text { membrane staining of } \\
>30 \% \text { invasive tumor } \\
\text { cells) }\end{array}$ & $>4.0$ & $>6.0$ & $\geq 2.0$ & $>2.2$ \\
\hline
\end{tabular}

Abbreviations: ASCO/CAP, American Society of Clinical Oncology/College of American Pathologists; CEP17, chromosome enumeration probe 17; IHC, immunohistochemistry; FDA, Food and Drug Administration; FISH, fluorescence in situ hybridization. 
provide clear guidance for HER2 assessment, interpretation of test results can be rendered difficult by complexities of breast tumor biology, such as aneusomy of chromosome 17 (including polysomy or monosomy), colocalization of the CEP17 and the HER2 signals, and intratumoral genetic heterogeneity. ${ }^{20}$ As monosomy and colocalization are rare, this review focuses on polysomy of chromosome 17 and genetic heterogeneity. We summarize the evidence relating to these issues and discuss its relevance for the interpretation of HER2 tests and trastuzumab eligibility in clinical practice (summarized in Figures 1 and 2).

\section{Polysomy 17}

Gene amplification refers to an increase in the copy number of a specific chromosomal region and is commonly linked to overexpression of the affected genes. ${ }^{21}$ Well over $90 \%$ of HER2-overexpressing breast tumors show focal gains involving the HER2 locus. $^{22}$ In contrast, polysomy is defined by the presence of extra copies of one or more whole chromosomes. Although polysomy of chromosome 17 provides an alternative mechanism for increasing HER2 gene dosage, its effect on HER2 expression, other clinicopathologic variables, prognosis, and treatment response is not well established. Nonetheless, these are important issues, as elevated
CEP17 count ('polysomy') is frequently reported in breast cancer $^{23}$ and is a major reason for discordant ISH status, depending on whether mean HER2 copy number or HER2:CEP17 ratio is used. ${ }^{24,25}$ Some have argued that correction for chromosome 17 copy number is essential for accurately defining HER status, ${ }^{19,24}$ but others have questioned this view. ${ }^{26,27}$ Currently, there is no consensus on whether or how elevated CEP17 count ('polysomy') should be integrated into HER2 test interpretation.

\section{Defining Polysomy 17}

In the absence of cytogenetic analysis, the number of CEP17 signals observed by ISH has generally been used as a surrogate for chromosome 17 copy number (Figures 3 and 4). However, the appropriate CEP17 copy cutoff to define elevated CEP17 status ('polysomy') is not obvious, as even truly disomic samples may deviate from the expected value of 2 because of sectioning artifacts, the presence of $\mathrm{G}_{2}$ cells, and chromosomal instability. ${ }^{28}$ Several definitions have been proposed, and none is accepted as standard, ${ }^{28-51}$ but a mean of $\geq 3$ CEP17 signals per nucleus is a commonly adopted threshold, ${ }^{2}$ with most studies using this definition, including large cohort ( $\geq 100$ cases) studies.

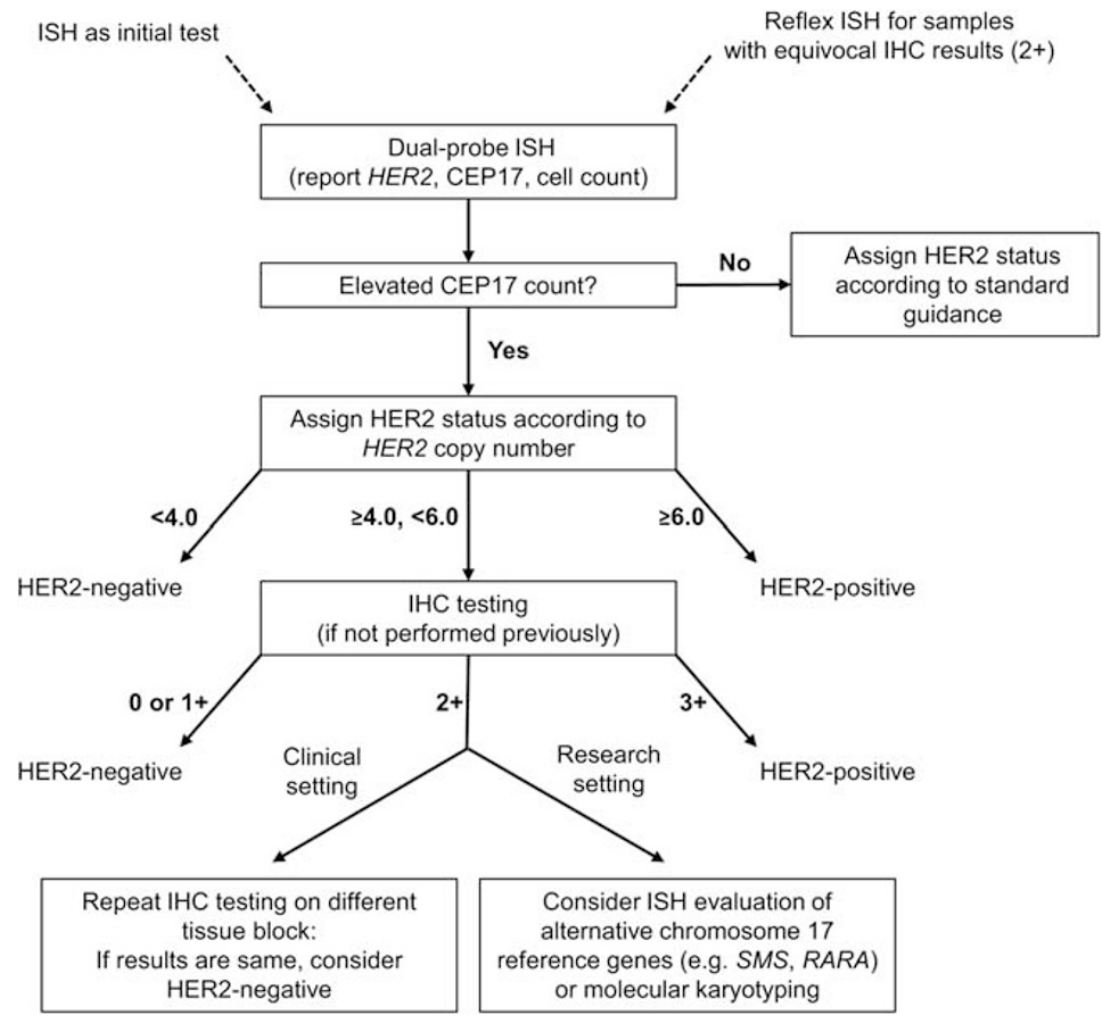

Figure 1 Consensus algorithm for human epidermal growth factor receptor 2(HER2) status determination in breast cancer samples with apparent polysomy 17 (increased chromosome enumeration probe 17 (CEP17) count). IHC, immunohistochemistry; ISH, in situ hybridization. 


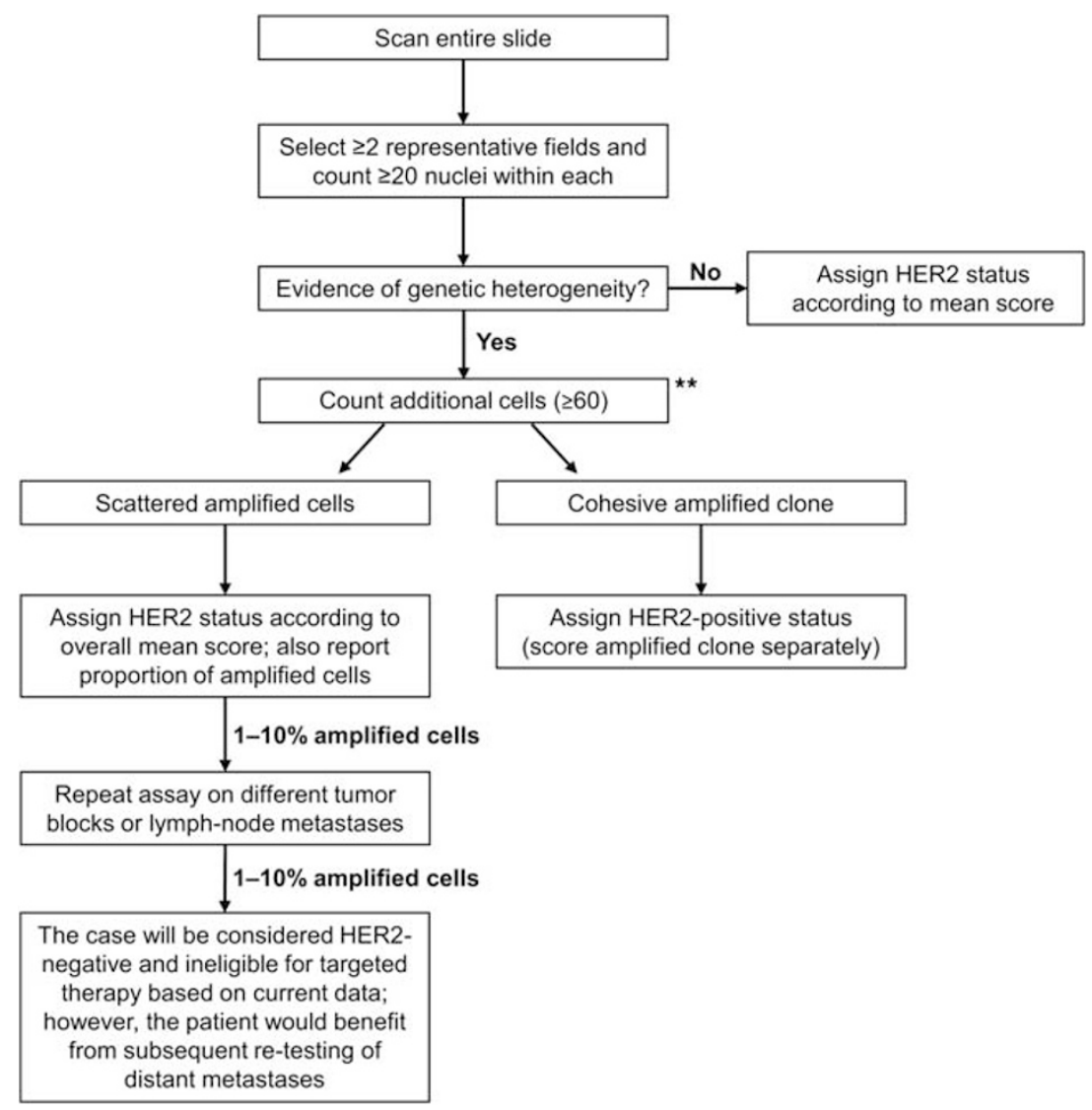

Figure 2 Consensus algorithm for human epidermal growth factor receptor 2 (HER2) status determination in breast cancer samples showing genetic heterogeneity. **Match with IHC stained slides.
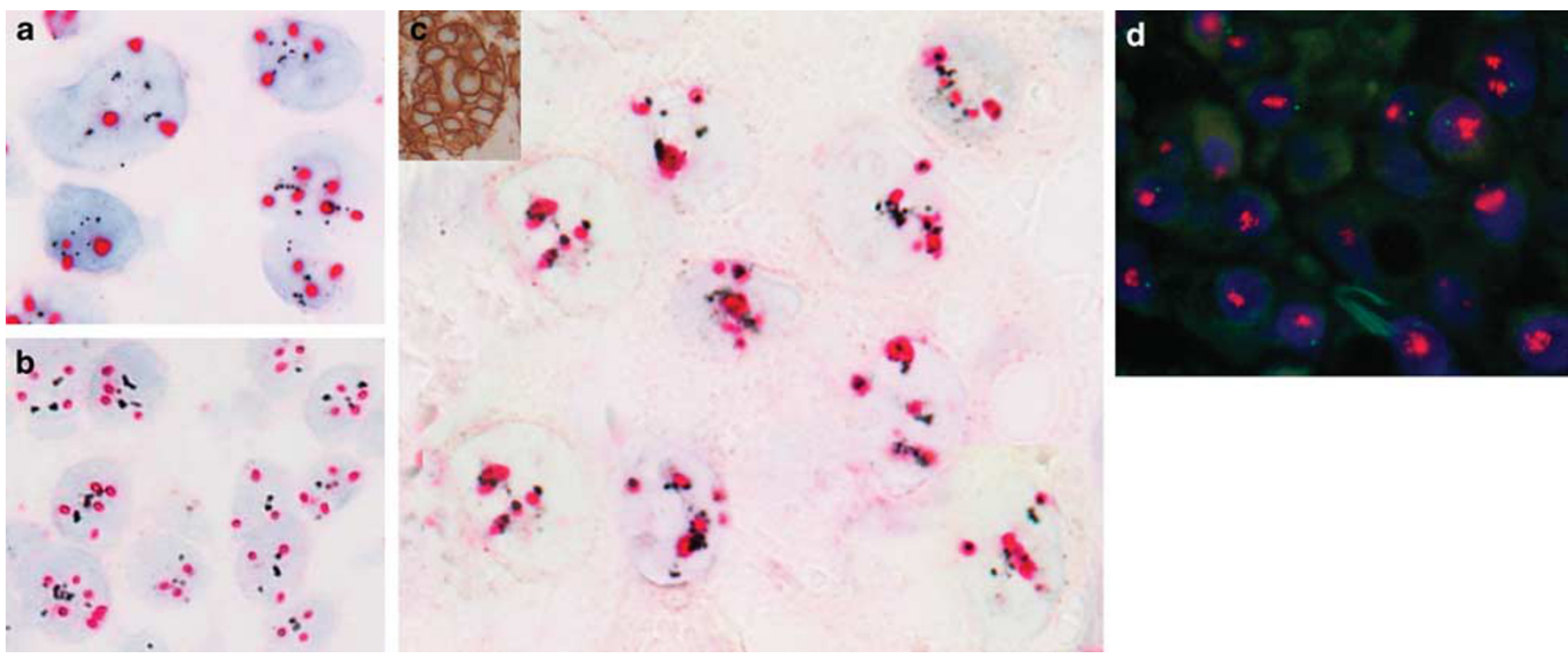

Figure 3 Breast tumor cells analyzed by dual-color silver in situ hybridization, using human epidermal growth factor receptor 2 (HER2) (black) and chromosome enumeration probe 17 (CEP17) (red) probes, showing apparent polysomy 17 (increased CEP17 count) with HER2 amplification (a), increased CEP17 count without HER2 amplification (b), and coamplification of HER2 and CEP17 (c), with strong HER2 overexpression (inset: immunohistochemistry (IHC) $3+$ ). Monosomy with HER2 amplification (d) is demonstrated by fluorescent in situ hybridization, using HER2 (red) and CEP17 (green) probes.

\section{Prevalence of Polysomy 17 in Breast Cancer}

Defined by the relevant authors as an elevated CEP17 count, 'polysomy 17 ' is a common finding in invasive breast cancer series. ${ }^{28-51}$ Using the definition of $\geq 3$ CEP17 copies per cell, reported prevalence rates range between $3 \%$ and $46 \%$ (Table 2)..$^{30-32,34,36-38,41-47,50-51}$ The wide variation 


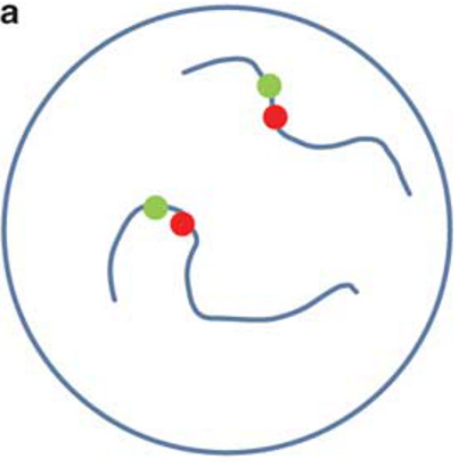

Disomic, HER2-nonamplified

c

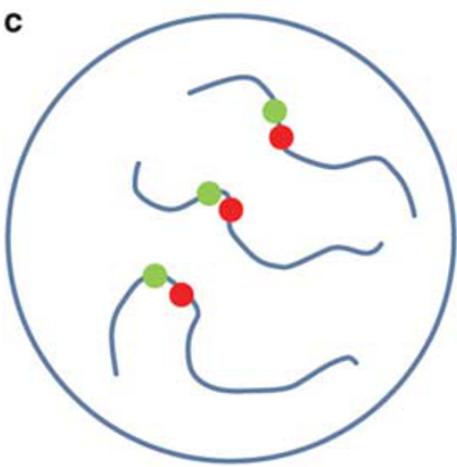

Polysomic, HER2-nonamplified b

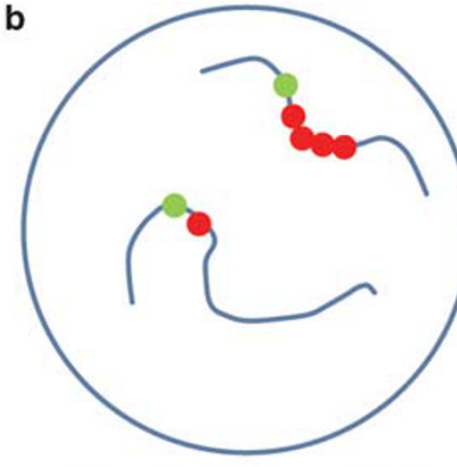

Disomic, HER2-amplified

d

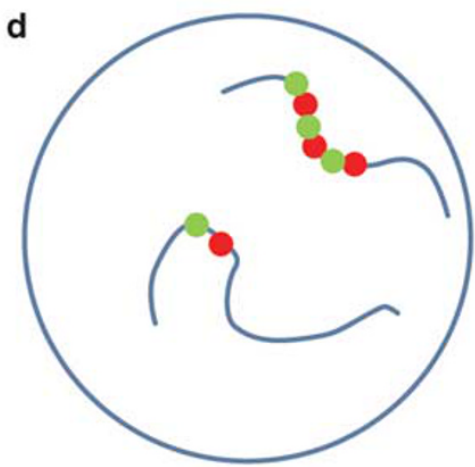

Disomic, HER2/CEP17-coamplified

Figure 4 Schematic diagrams showing nuclei with (a) disomy, human epidermal growth factor receptor 2 (HER2)-unamplified; (b) disomy, HER2-amplified; (c) polysomy, HER2-unamplified; (d) HER2/chromosome enumeration probe 17 (CEP17) coamplification.

Table 2 Prevalence of elevated CEP17 count ('polysomy') in breast cancer series

\begin{tabular}{|c|c|c|c|}
\hline Study & Sample & Definition & $\begin{array}{l}\text { Prevalence } \\
\quad(\%)\end{array}$ \\
\hline Bose et $a l^{30}$ & $\begin{array}{l}\text { Breast cancer with equivocal or weakly positive }(n=52) \text { or negative } \\
(n=22) \text { IHC result }\end{array}$ & CEP17 copy $\geq 3$ & 34 \\
\hline Cuadros et $a l^{31}$ & Breast carcinoma $(n=462)$ & Mean CEP17 $\geq 3$ & 38 \\
\hline $\begin{array}{l}\text { Downs-Kelly } \\
\text { et } a l^{32}\end{array}$ & Consecutive breast cancer cases $(n=727)$ & Mean CEP17 $\geq 3$ per cell & 8 \\
\hline Hofmann et $a l^{34}$ & Metastatic breast cancer with IHC $3+$ or HER2:CEP17 $\geq 2.0(n=95)$ & Mean CEP17 $\geq 3 /$ cell & 27 \\
\hline Kokate et $a l^{36}$ & Invasive breast cancer with nonequivocal FISH ratio $(n=390)$ & Mean CEP17 > 3 & 7 \\
\hline $\begin{array}{l}\text { Krishnamurti } \\
\text { et } a l^{37}\end{array}$ & Invasive breast carcinoma $(n=365)$ & Mean CEP17 $\geq 3 /$ cell & 23 \\
\hline Merola et $a l^{38}$ & Breast carcinoma, IHC $2+(n=343)$ & Mean CEP17 copy >3 & 46 \\
\hline Petroni et $a 1^{52}$ & Invasive ductal breast cancer $(n=647)$ & Mean CEP17 $\geq 3$ & 27 \\
\hline Salido et $a l^{41}$ & $\begin{array}{l}\text { Consecutive breast cancer cases, IHC } 0-3+(n=50) \text { or IHC } 2+/ 3+ \\
(n=125)\end{array}$ & Mean CEP17 $\geq 3$ per cell & 13 \\
\hline Takehisa et $a l^{42}$ & $\begin{array}{l}\text { Presurgery fine-needle aspiration cytology samples from primary breast } \\
\text { cancer patients }(n=40)\end{array}$ & $\begin{array}{l}>3 \text { CEP17 signals in }>20 \% \\
\text { of nuclei }\end{array}$ & 43 \\
\hline Torrisi et $a l^{43}$ & Breast cancer with IHC $0-2+(415)$ or IHC $3+(n=42)$ & CEP17 copy $\geq 3$ & 17 \\
\hline $\begin{array}{l}\text { Tsukamoto } \\
\text { et } \text { al }^{44}\end{array}$ & Invasive ductal carcinoma $(n=113)$ & $\begin{array}{l}>20 \% \text { nuclei with CEP17 } \\
>3\end{array}$ & 37 \\
\hline Tubbs et $a l^{45}$ & Primary breast carcinomas $(n=742)$ & $\begin{array}{l}\text { CEP17 count } \geq 3 \text { in } 80 \% \text { of } \\
\text { cells }\end{array}$ & 3 \\
\hline $\begin{array}{l}\text { Vanden Bempt } \\
\text { et } a l^{46}\end{array}$ & $\begin{array}{l}\text { Primary invasive breast cancer, IHC } 2+/ 3+(n=171) \text { or IHC } 0 / 1+ \\
(n=55)\end{array}$ & Mean CEP17 $\geq 3$ per cell & 46 \\
\hline Varshney et $a l^{47}$ & Invasive breast cancer $(n=687)$ & Mean CEP17 copy $\geq 3$ & 10 \\
\hline Żaczek et al ${ }^{50}$ & Stage I-III breast cancer $(n=149)$ & $\begin{array}{l}\geq 3 \text { CEP17 signals in }>30 \% \\
\text { of nuclei }\end{array}$ & 40 \\
\hline Zhu et $a l^{51}$ & Invasive breast cancer $(n=481)$ & Mean CEP17 $\geq 3$ per cell & 28 \\
\hline
\end{tabular}

Abbreviations: CEP17, chromosome enumeration probe 17; IHC, immunohistochemistry; FISH, fluorescence in situ hybridization. 
in estimates may be attributable both to differences in tumor characteristics and the CEP17 cutoff adopted.

\section{Polysomy 17 and Clinicopathologic Features}

Along with HER2, chromosome 17 contains several other genes implicated in tumorigenesis (eg, BRCA1, TOP $2 A$, TP53), ${ }^{23}$ raising the possibility that polysomy might influence clinicopathologic and prognostic variables due to altered expression of these growth-regulatory genes/proteins. Several studies have linked elevated CEP17 count ('polysomy') with unfavorable pathologic features compared with disomic tumors. In unselected breast carcinoma series, polysomy/aneusomy 17 have been associated with increased proliferative activity and greater Nottingham Prognostic Index (NPI) score, although data regarding nodal involvement, histologic grade, and hormone receptor status are conflicting. ${ }^{42,49,52}$ In contrast, a prospective analysis restricted to IHC $2+/ 3+$ tumors $(n=147)$ found a significant association between elevated CEP17 count ('polysomy') (defined as CEP17 $\geq 3$ ) and node positivity, but not histologic grade or hormone receptor status. ${ }^{41}$ These studies found no significant impact of polysomy on survival, although a trend toward greater relapse was reported for polysomic, IHC $2+/ 3+$ tumors. $^{41,42,49}$

There is evidence that elevated CEP17 count ('polysomy') might confer a more aggressive phenotype in the absence of specific HER2 amplification. In a comparison of breast carcinomas with normal HER2:CEP17 ratios, elevated CEP17 count ('polysomy') (CEP17 $\geq 3 ; n=44$ ) was associated with higher nuclear and histologic grade, greater mitotic activity, poorer NPI score, and estrogen receptor (ER) negativity compared with non-polysomic tumors $(n=36) .{ }^{37}$ Indeed, the pathologic features of polysomic HER2-nonamplified tumors showed a trend toward those with specific HER2 amplification $(n=35)$. In contrast, Vanden Bempt et al ${ }^{46}$ found no significant differences between polysomic (CEP17 $\geq 3$ ) and non-polysomic primary breast cancers (both groups without HER2 amplification) in clinicopathologic variables, including histologic grade, tumor size, NPI, nodal status, or hormone receptor positivity. Consistent with another study, ${ }^{43}$ polysomic, HER2-nonamplified tumors had more favorable pathologic features compared with HER2-amplified tumors. Although patients with polysomic, nonamplified tumors had superior disease-free survival (DFS) compared with HER2amplified tumors $(P=0.031)$, there was a trend toward decreased survival with polysomic versus non-polysomic tumors in the absence of HER2 amplification $(P=0.056){ }^{46}$

Despite numerous inconsistencies between the studies, these data provide some indications that elevated CEP17 count ('polysomy') may be associated with unfavorable clinicopathologic variables and poorer prognosis, albeit to a lesser extent than HER2 amplification.

\section{Polysomy 17 and HER2 Overexpression}

Gene amplification is thought to be the primary genetic mechanism underlying HER2 overexpression, but increased gene dosage secondary to polysomy 17 could also contribute to increased protein levels. Several studies have correlated elevated CEP17 count ('polysomy') with increased IHC score in tumors without specific HER2 amplification. ${ }^{29,35,47,53}$ For example, Hyun et $a l^{35}$ reported a significantly higher incidence of elevated CEP17 count ('polysomy') (CEP17 > 2.25) in tumors with IHC $2+/ 3+$ versus IHC $0 / 1+$ results $(40.8 \%$ versus $12.3 \%, P<0.001)$. In the absence of HER2 amplification, elevated CEP17 count ('polysomy') has been commonly associated with equivocal IHC results (IHC $2+$ ). ${ }^{30,38,41,46,52}$ In the series of Vanden Bempt and co-workers, ${ }^{46} 46$ of 62 polysomic, HER2nonamplified $(74.2 \%)$ tumors tested IHC $2+$, but none were IHC $3+$. However, other studies have associated elevated CEP17 count ('polysomy'), particularly high CEP17 counts (CEP17 $\geq 4$ ), with IHC $3+$ staining. $^{25,47,52}$ In one series, 17 of 150 (9.8\%) polysomic, HER2-nonamplified tumors showed positive $(3+)$ immunohistochemistry staining compared with 6 of 247 (1.5\%) eusomic, HER2-nonamplified cases. ${ }^{52}$

Others have found no evidence that elevated CEP17 count ('polysomy') contributes to HER2 overexpression. In a series of 584 breast cancers with normal HER2:CEP17 ratios, there was no significant difference in HER2 protein expression (IHC $0 / 1+/ 2+v s 3+$ ) between tumors with normal versus increased CEP17 count $(\leq 2.25$ versus $>2.25$ per cell). ${ }^{24}$ In another study of 56 HER2nonamplified breast cancers showing elevated CEP17 count ('polysomy') (CEP17 $\geq 2.1$ ), IHC was mostly 0 or $1+(70 \%)$, with some $2+(27 \%)$ and a minority scoring $3+(4 \%){ }^{32}$

Taken together, the balance of evidence suggests that elevated CEP17 count ('polysomy') may have a role in overexpression of HER2, particularly in tumors with IHC $2+$ scores. Interestingly, there is little evidence that polysomy 17 upregulates HER2 mRNA, ${ }^{32,54}$ a fact that has led some to propose post-translational mechanisms to account for HER2 protein increases. ${ }^{32}$

We hypothesize that the regulation of HER2 expression may differ between cases showing selective HER2 amplification, segmental HER2/CEP17 (or other) coamplifications, or true polysomy. The biological impact of such changes in genome organization may be rather heterogeneous, in line with contradictory reports of the correlation between apparent chromosome 17 polysomy and HER2 overexpression. ${ }^{24-26}$ As a result, it may be 
important to obtain additional information on the HER2 locus and its expression profile at the mRNA and protein levels, going beyond the limited information that is provided by FISH using only two probes.

\section{Polysomy 17 and Response to Anti-HER2 Therapy}

The potential association between elevated CEP17 count ('polysomy') and HER2 expression raises the question of whether increased chromosome 17 copy number influences trastuzumab response. This is particularly important in the context of patients, with a polysomy-associated IHC $3+$ score but negative FISH ratio, who might be assumed to have a 'false-positive' IHC result and therefore be considered ineligible for trastuzumab. To address this question, Hofmann et $a l^{34}$ performed a retrospective analysis of trastuzumab response by CEP17 status using data from a Phase II study of first-line trastuzumab monotherapy in 105 patients with HER2 + (IHC $3+$ or FISH-amplified) metastatic breast cancer. Elevated CEP17 count ('polysomy') $($ CEP17 $\geq 3)$ was observed in 26 patients $(27 \%)$, of whom six responded to trastuzumab. All six had documented IHC $3+$ scores, while four had a HER2:CEP17 ratio $\geq 2.0$. The remaining two responders had negative FISH ratios $(<2.0)$ and elevated mean HER2 copy number owing to polysomy. This supports the concept that some patients with HER2 overexpression due to polysomy rather than amplification will respond to trastuzumab and suggests that IHC $3+$ tumors should be considered HER2 + irrespective of the FISH result.

Further data supporting the trastuzumab sensitivity of polysomic tumors emerged from the CALGB 150002 study, ${ }^{55}$ a correlative companion to the pivotal 9840 trial, which randomized a locally tested, HER2-negative metastatic breast cancer cohort to receive paclitaxel with or without trastuzumab. ${ }^{56}$ Of 192 tumors with a normal HER2:CEP17 ratio $(<2.0)$ on central testing, $38(20 \%)$ were found to have elevated CEP17 count ('polysomy') (CEP17 $\geq 2.2$ ). The vast majority of these polysomic tumors (34/37; $92 \%)$ tested negative/equivocal for HER2 overexpression (IHC $0 / 1+/ 2+$ ). In contrast to the HER2-negative cohort as a whole, the subgroup of patients with HER2-nonamplified, polysomic tumors derived significant benefit in terms of overall response rate with paclitaxel plus trastuzumab versus paclitaxel alone ( $63 \%$ vs $26 \%, P=0.048)$. These data suggest that trastuzumab may be efficacious in polysomic, HER2-nonamplified tumors, even in the absence of an unequivocally positive IHC result. In contrast, a subgroup analysis of the Phase III EGF30001 trial revealed no significant benefit with first-line lapatinib plus paclitaxel versus paclitaxel alone in patients with HER2-nonamplified, polysomic metastatic breast cancer. ${ }^{57}$
The impact of elevated CEP17 count ('polysomy') has also been evaluated in a retrospective analysis of the Phase III HERceptin Adjuvant (HERA) trial, which randomized women with HER2 + early breast cancer who had completed locoregional therapy and at least four cycles of (neo)adjuvant chemotherapy, to 1 or 2 years of trastuzumab or to undergo observation alone. ${ }^{9,58}$ Among patients with a positive FISH ratio, 883 of 2030 (43\%) had elevated CEP17 count ('polysomy') ( $\geq 3$ CEP17 signals in $\geq 30 \%$ of nuclei). Importantly, in this HER2 + population (centrally confirmed IHC $3+$ or HER2:CEP17 $\geq 2.0$ ), trastuzumab maintained consistent DFS benefit across the subgroups of patients with or without elevated CEP17 count ('polysomy'). These results suggest that the efficacy of adjuvant trastuzumab in patients with HER2 + early breast cancer, assessed according to standard criteria, is unaffected by elevated CEP17 count. Only 41 patients were diagnosed as HER2 + despite a FISH ratio $<2.0$; this number is too small to determine whether adjuvant trastuzumab was beneficial. Elevated CEP17 count ('polysomy') might also predict response to other therapies. For example, increased copy number of the gene for topoisomerase II, via gene amplification or polysomy 17 , has been associated with sensitivity to anthracycline-based neoadjuvant therapy. ${ }^{59}$

\section{True Polysomy or CEP17 Amplification?}

Standard ISH analyses generally assume that the number of CEP17 signals corresponds to the number of chromosome 17 copies. However, concurrent evaluation of several chromosome 17 genes using multiple-probe FISH or multiplex ligation-dependent probe amplification (MLPA) suggests that focal amplifications encompassing the centromere are the usual reason for high-level increases in CEP17 signals. ${ }^{17,60,61}$ Of 171 breast tumors with apparent polysomy (CEP17 >2.6), only 24 cases (14\%) showed the equivalent increases in copy numbers of CEP17, HER2, SMS, RARA, and TP53 that would result from whole chromosomal gains. ${ }^{17}$ Similarly, MLPA analysis of 17 chromosome 17 loci identified no cases of true polysomy among 111 breast cancers, although $19 \%$ had shown CEP17 increases by CISH. ${ }^{60}$

Molecular karyotyping studies have confirmed the rarity of true polysomy 17 in breast cancer. For example, Marchiò et al ${ }^{62}$ used array-comparative genomic hybridization (aCGH) to make a detailed assessment of chromosome 17 status in 18 breast tumors with apparent polysomy 17 (CEP17 $\geq 3$ ). Strikingly, only one case demonstrated gains of both the short and long arms of the chromosome, which is a requirement for a true polysomic state. The remainder showed gains of $17 \mathrm{q}$ with centromeric involvement $(n=11), 17 \mathrm{q}$ gain without centromeric involvement $(n=1)$, or focal centromeric amplification 
$(n=5)$. Similarly, an aCGH analysis of 97 breast cancer specimens found no cases of true polysomy, despite the inclusion of two cases with elevated CEP17 copy number. ${ }^{63}$ Single-nucleotide polymorphism karyotyping has also shown that true polysomy 17 is uncommon. ${ }^{25}$

Collectively, these studies show that elevated CEP17 copy number is not a useful surrogate for polysomy 17 and that most cases previously assigned 'polysomic' status actually represent focal pericentromeric gains.

\section{Authors' Consensus Recommendations}

The erroneous assumption that the number of CEP17 signals observed by ISH corresponds to the number of chromosome 17 copies may explain many of the inconsistencies in the polysomy literature. Tumors with abnormal CEP17 copy number may, in fact, represent a heterogeneous group with complex chromosomal gains and losses, whose clinicopathologic features may be dependent on the specific genetic changes present. In the research setting, we recommend the use of more sophisticated techniques (eg, aCGH) to define more accurately the chromosome 17 status of a tumor, and to help clarify the biologic significance of these genetic aberrations in patients with breast cancer.

In the meantime, these findings have practical implications for interpretation of HER2 tests in clinical practice (Figure 1). ${ }^{64,65}$ Importantly, use of the HER2:CEP17 ratio in isolation may be misleading in cases with CEP17 gains or losses, which would lead to under- and overestimation of HER2 amplification, respectively. We therefore recommend that raw ISH data (cell count, absolute HER2, and CEP17 signals) be included in pathology reports to assist interpretation. ${ }^{61}$ In cases with elevated CEP17 count, it is advisable to use mean HER2 copy number ( $\geq 6$ copies) for defining HER2 status. This approach is supported by the high concordance between IHC staining intensity and mean copy number in the HERA trial ${ }^{66}$ and between IHC and single-probe SISH results $(98.3 \%)$ in a recent analysis of more than 1200 breast cancers. ${ }^{67}$ In this latter study, the result of single-probe SISH was more closely correlated than dual-probe SISH with IHC score, among tumors with discordant single- versus dual-probe ISH assessment. Although Bartlett et $a l^{68}$ in 2008 recommended use of the HER2:CEP17 ratio for samples with CEP17 elevation, this study predates the bulk of the data showing that true polysomy is rare. Using patient screening data from the HERA trial, we estimated that the use of mean copy number alongside the ratio would identify an additional 29 patients ( $0.5 \%$ of all FISH tests) for trastuzumab eligibility (J Rüschoff et al, personal communication). The same approach being applied to the series of Vanden Bempt et $a l^{46}$ and Dal Lago et $a l^{24}$ would yield an additional $2.2 \%$ and $1.5 \%$ of patients as 'HER2 +', respectively.

We also note that confirmatory IHC can provide useful supporting information in complex cases. ${ }^{61}$ For those patients whose diagnostic picture remains unclear, the use of additional ISH probes for alternative reference genes, such as RARA and $S M S$, may help resolve ambiguous HER2 status. ${ }^{17}$ Finally, we anticipate an increasing role for molecular karyotyping techniques in supporting HER2 status determination for complex cases. ${ }^{69}$ In a study of 20 samples referred because of discordance, equivocal results, or suspected pericentromeric aneusomy, aCGH was able to resolve HER2 status accurately in all cases. ${ }^{70}$ Notably, 16 cases displayed complex rearrangements of chromosome 17, although one showed true polysomy with low-level HER2 amplification, and a second tumor was monosomic.

In conclusion, we consider that HER2 status is best defined by evaluating IHC score, mean HER2 copy number, and HER2:CEP17 ratio. Samples scoring IHC $3+$ should be scored HER2 + (taking into account well-controlled methods for assessment), regardless of ISH result and elevated CEP17 count ('polysomy'). When the mean HER2 copy number is $\geq 6$, and the IHC score is $2+$, tumors should be assessed as HER2 +, irrespective of HER2:CEP17 ratio. Such a strategy will help ensure that patients who may benefit from trastuzumab are not denied access to this potentially life-saving therapy.

\section{Genetic heterogeneity}

Cancer-associated mutations often exhibit nonuniform distributions among tumor cells. ${ }^{71}$ In its broadest sense, 'HER2 genetic heterogeneity' describes the coexistence of multiple tumor-cell subpopulations with distinct HER2 amplification characteristics within the same individual (Figures 5 and 6). The term encompasses both intratumoral heterogeneity, where HER2 gene status differs between cells in the same or different regions of a single tumor, and intertumoral heterogeneity, where there is discordance between a primary tumor and its metastases. ${ }^{72}$ Two main distributions of intratumoral heterogeneity have been described: a 'clustered' form characterized by pockets of highly amplified cells, sometimes possessing distinct histologic architecture or grade, and a 'mosaic' form in which distinct subpopulations comingle, although some argue that this mosaic pattern is, in fact, an ISH artifact. ${ }^{72-74}$

Genetic heterogeneity is clinically relevant in two major respects. First, heterogeneity could lead to discordant HER2 status between blocks of the same tumor, in core biopsies versus surgical specimens, in primary tumors versus metastases, among results of different laboratories, and between IHC and ISH assays. Second, the potential relevance of 

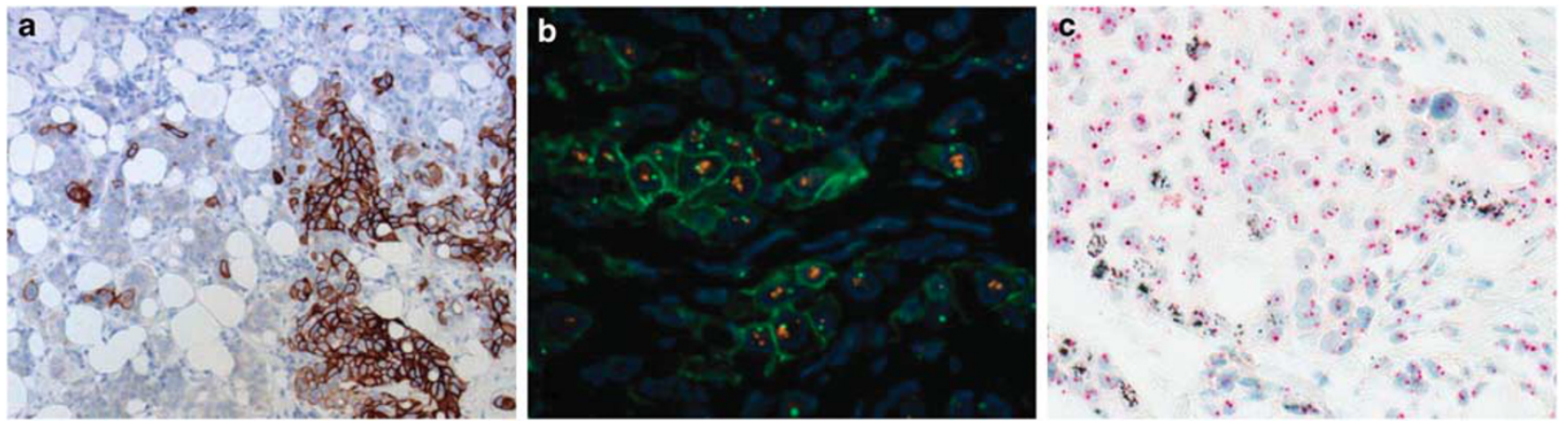

Figure 5 Genetically heterogeneous tumors analyzed by different methods. (a) Immunohistochemistry (IHC) of a genetically heterogeneous breast tumor showing clusters of human epidermal growth factor receptor 2 (HER2) + cells (brown staining). (b) Double fluorescence in situ hybridization/IHC staining showing heterogeneity made up of tumor cells showing both HER2 protein overexpression (green membrane staining) and HER2 gene amplification (red signals). (c) Genetically heterogeneous tumor analyzed using dual-hapten, dual-color in situ hybridization (HER2, black staining; chromosome enumeration probe 17, red staining).

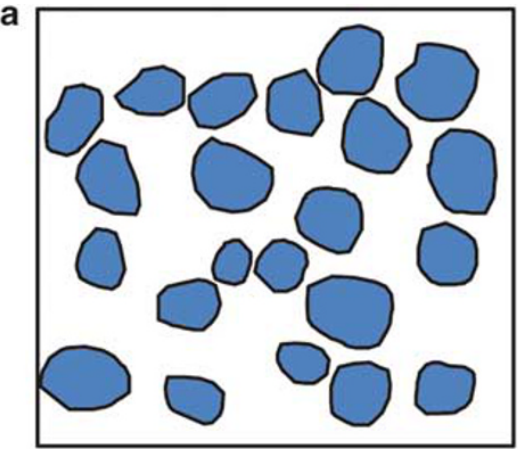

HER2-nonamplified, genetically homogeneous

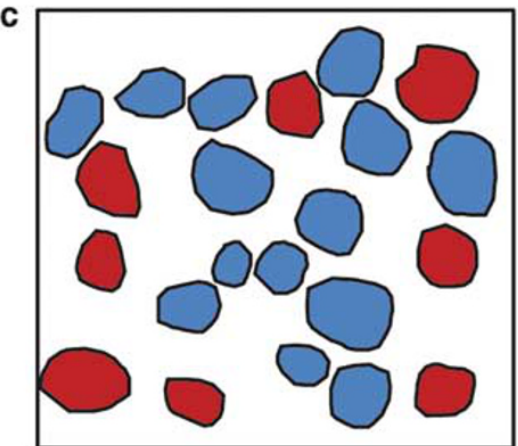

Genetically heterogeneous for HER2 amplification (scattered amplified cells) b

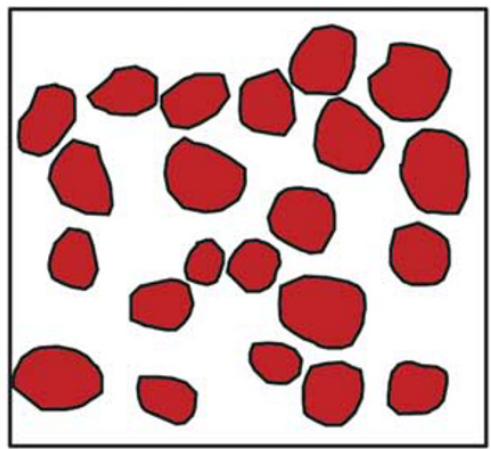

HER2-amplified, genetically homogeneous

d

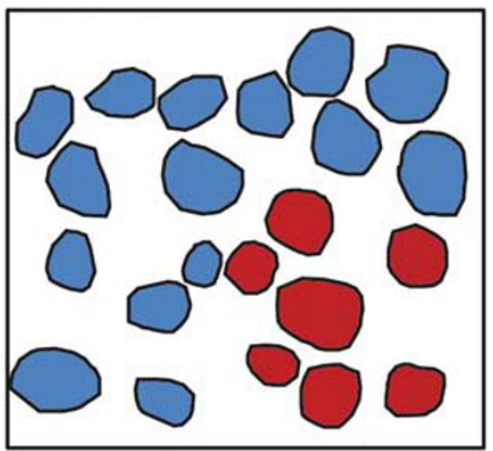

Genetically heterogeneous for HER2 amplification (amplified cluster)

Figure 6 Schematic diagrams illustrating breast cancer specimens with (a) human epidermal growth factor receptor 2 (HER2)-nonamplified, genetically homogeneous tumor; (b) HER2-amplified, genetically homogeneous tumor; (c) genetically heterogeneous tumor with 'mosaic' pattern in which amplified and unamplified clones comingle; (d) genetically heterogeneous tumor with a cohesive clone of amplified cells surrounded by nonamplified cells. Blue polygons represent nuclei with a normal HER2:CEP17 ratio ( $\leq 2.2)$; red polygons represent nuclei with an elevated HER2:CEP17 ratio $(>2.2)$.

subpopulations of HER2-amplified cells within otherwise nonamplified tumors has been a topic of debate, particularly regarding prognostic significance and potential benefit from trastuzumab.

\section{Defining Genetic Heterogeneity}

Although genetic heterogeneity has been variously defined in terms of regional differences in HER2 
amplification, ${ }^{75,76}$ a standardized approach for assessment of nonuniform HER2 amplification was published in 2009 by a College of American Pathologists Expert Panel. ${ }^{74}$ This guideline defines genetic heterogeneity according to the presence of $>5 \%$ but $<50 \%$ of infiltrating tumor cells with a HER2:CEP17 ratio $>2.2$ (or mean HER2 copy number >6). In heterogeneous cases, the Panel also recommends that the proportion of invasive tumor cells showing HER2 amplification be reported alongside the mean value for all cells analyzed, with separate analysis of any clusters present.

Although not based on outcomes data, an explicit goal of this guideline was to standardize the definition of genetic heterogeneity to facilitate future study of its clinical relevance. Nonetheless, some have questioned the recommendation for routine reporting on a histopathologic phenomenon for which clinical significance remains poorly defined. ${ }^{77}$ Others have suggested that the upper limit for amplified cells should be increased to 95\% so that tumors with mixed populations in which HER2-amplified cells predominate (ie, 50-95\% cells) are also captured within the definition. ${ }^{78}$ Some researchers have argued that the proportion of amplified cells is not a useful measure of nonuniformity within a tumor. ${ }^{79}$ The College of American Pathologists guideline also introduces an apparent discrepancy in assessment between ISH and IHC methods: whereas homogeneous ISH positivity requires $\geq 50 \%$ amplified cells, HER2 positivity defined according to IHC requires adequate staining in $>10 \%$ of cells (Food and Drug Administration cutoff) or $>30 \%$ of cells (American Society of Clinical Oncology and College of American Pathologists cutoff). As the same tumor-cell populations in heterogeneous tumors show both HER2 protein overexpression and HER2 gene amplification (Figure 5), this disparity is liable to introduce discordance between IHC and ISH results.

Alternative definitions of genetic heterogeneity include that from the Italian Society of Human Genetics (SIGU), which recommends that different subclones be identified according to cytogenetic pattern (ie, low, high, or absence of amplification) and FISH ratio reported separately for each subpopulation present. $^{73}$ UK guidelines define genetic heterogeneity according to the observation of distinct fields within the tumor showing amplified and nonamplified HER2:CEP17 ratios. ${ }^{80}$ Recently, Bartlett and co-workers ${ }^{81}$ suggested classifying heterogeneity with amplification as simple, complex, or isolated amplified tumor cells, and provided reporting recommendations for these cases.

\section{Prevalence of Genetic Heterogeneity}

Although an early application of the College of American Pathologists definition found a low prevalence of genetic heterogeneity in primary breast carcinomas $(40 / 742,5 \%),{ }^{45}$ more recent studies suggest that a third or more of breast tumors exhibit heterogeneous HER2 amplification (11-40\%; Table 3). ${ }^{28,40,79,82-84}$ Of note, one study reported a far higher rate of genetic heterogeneity when defined by HER2:CEP17 ratio (23\%) than with mean HER2 copy number $(7 \%)$, raising some concerns over the validity of the College of American Pathologists criterion. ${ }^{82}$ In another study, consideration of genetic heterogeneity tripled the proportion of patients with HER2 abnormalities (ie, amplified and/or heterogeneous, 45\%) compared with HER2 amplification alone (14\%). ${ }^{83}$

Intratumoral heterogeneity is also observed at the level of HER2 protein overexpression (Figures 5a and b). In the Adjuvant Lapatinib and/or Trastuzumab Treatment Optimization (ALTTO) study, 1091 of 8490 patients $(12.85 \%)$ had tumors with IHC3 + staining in $1-50 \%$ of cells ( $G$ Viale, personal communication). Similarly, 3.7\% of patients enrolled in the N9831 study had tumors with IHC3 + staining in $10-30 \%$ of cells. ${ }^{85}$

\section{Impact of Genetic Heterogeneity on HER2 Status Determination}

Intratumoral genotypic variability could lead to discrepant HER2 status depending on the region analyzed, and so might introduce sampling errors into HER2 testing. Brunelli et $a l^{75}$ estimated that $13 \%$ of tumors with low-grade HER2 amplification

Table 3 Prevalence of College of American Pathologists-defined HER2 genetic heterogeneity in published studies

\begin{tabular}{|c|c|c|c|}
\hline Study & Sample & Parameter & Prevalence (\%) \\
\hline Tubbs et $a l^{45}$ & Consecutive primary breast carcinomas $(n=742)$ & HER2:CEP17 ratio & 5 \\
\hline Öhlschlegel et $a l^{40}$ & Consecutive invasive breast carcinomas $(n=218)$ & HER2:CEP17 ratio & 15 \\
\hline Allison et $a l^{82}$ & Consecutive clinical breast cancers $(n=1329)$ & HER2:CEP17 ratio & 23 \\
\hline & & HER2 copy number & 7 \\
\hline Chang et $a l^{79}$ & Consecutive breast carcinomas $(n=2522)$ & HER2:CEP17 ratio & 26 \\
\hline Bartlett et $a l^{83}$ & Breast cancers analyzed in UK routine practice or for a clinical trial $(n=6461)$ & HER2:CEP17 ratio & 34 \\
\hline Murthy et $a l^{28}$ & Invasive ductal carcinoma, IHC $2+(n=60)$ & HER2:CEP17 ratio & 40 \\
\hline Seol et $a l^{84}$ & Invasive primary breast cancer $(n=96)$ & HER2:CEP17 ratio & 11 \\
\hline
\end{tabular}

Abbreviations: CEP17, chromosome enumeration probe 17; HER2, human epidermal growth factor receptor 2; IHC, immunohistochemistry. 
exhibit regional genotypic variability that could affect trastuzumab eligibility. Similarly, a recent analysis of 291 nonconsecutive breast cancers showed that final FISH status was dependent on the area selected, section scored, and the number of cells analyzed. ${ }^{73}$ The authors also caution that focally amplified small populations might be missed in a single, randomly chosen section. In another study of 20 cases with genetic heterogeneity of the primary tumor, axillary node metastases showed loss of the minor HER2-amplified clone in $70 \%$ of cases. In the remainder, the amplified clone was retained either as a minority population (15\%) or as the predominant clone $(15 \%)$ within the nodes. ${ }^{86}$ Taken together, these studies highlight a need to standardize scoring methodology to ensure the accuracy of ISH testing. Currently, there is wide variation in practice, with different pathologists scoring a whole section, or specific areas selected at random or chosen as 'hot spots'. Furthermore, commercially available ISH kits variously define cutoffs for HER2 positivity according to examination of a certain number of nuclei (eg, 20 or more nuclei for FISH, dual-color CISH, SISH, BDISH, and DDISH) or a proportion of all cells analyzed (eg, $>50 \%$ nuclei for single-color CISH).

\section{Prognostic and Predictive Relevance of Genetic Heterogeneity}

As intended by the Expert Panel, studies are now exploring the clinical relevance of the College of American Pathologists definition. In a series of 345 core biopsy and resection specimens, Öhlschlegel and colleagues found genetic heterogeneity was significantly associated with elevated CEP17 count ('polysomy 17') (CEP17 > 2.25), absence of HER2 gene clusters ( $>16$ copies per nucleus), high histologic grade, and genomic instability. ${ }^{40}$ However, heterogeneity was not predictable from histologic, immunohistochemical, and DNA cytometric variables.

The prognostic impact of genetic heterogeneity has been assessed in a large cohort including clinical trial participants and patients from routine practice $(n=6461){ }^{83}$ In this study, there was no significant difference in 5-year DFS in patients with up to $30 \%$ of cells with a HER2:CEP17 ratio $>2.2$ compared with those without amplified cells, suggesting that a low proportion of amplified cells may not confer a worse prognosis. However, DFS was reduced among those with $30-100 \%$ of amplified cells. Based on an exploratory analysis of cases with $30-50 \%$ amplified cells, the investigators suggested that the prognosis was only worsened in the presence of an identifiable amplified clone, although the DFS difference did not reach statistical significance. Another recent study $(n=96)$ demonstrated that genetic heterogeneity was independently associated with poorer DFS compared with tumors with homogeneous HER2 amplification. ${ }^{84}$ These studies provide the first indications that subpopulations of HER2-amplified cells might drive poorer outcome.

From a therapeutic standpoint, the key question is whether genetically heterogeneous tumors respond to trastuzumab. Although the vast majority of such cases do not currently qualify for trastuzumab eligibility based on mean HER2:CEP17 ratio or mean HER2 copy number, ${ }^{82}$ genetically heterogeneous tumors harbor significant populations of HER2amplified cells and so might be sensitive to HER2-targeted therapy. ${ }^{40}$ Indeed, this phenomenon might account for the observation of trastuzumab responses in 'HER2-negative' tumors. ${ }^{82}$ In this respect, the results of the ongoing NSABP B-47 trial of adjuvant trastuzumab in HER2-low breast cancer are eagerly awaited.

\section{Authors' Consensus Recommendations}

One limitation of current guidelines for HER2 assessment is the difference in approach used to define HER2 positivity between IHC and ISH assays. In IHC, HER2-positivity is defined in terms of the percentage of cells with adequate staining, whereas most ISH techniques define HER2-positivity according to mean HER2 copy number or HER2/CEP17 ratio across the analyzed population. Although the College of American Pathologists definition of genetic heterogeneity incorporates information on the proportion of positive cells into the ISH assessment, it also introduces disparity between IHC and ISH methodology in the cutoff for proportion of cells showing HER2 abnormalities in the sample. Therefore, in heterogeneous cases and to ensure consistency with the Food and Drug Administration cutoff for IHC HER2-positivity of $10 \%$, we propose that tumors with $>10 \%$ HER2-amplified cells (after counting 20-60 cells from multiple different fields) should be considered HER2 +. We recommend that the percentage of amplified cells is included in the pathology report. Tumors containing a cohesive, amplified clone should be classed as HER2-amplified (with separate scoring for the clone), whereas tumors with scattered amplified cells should be classified according to the overall mean score (Figure 2). The prevalence of genetic heterogeneity and its potential to introduce sampling error into HER2 status determination highlight an urgent need to standardize ISH scoring methodology. We underscore the importance of scanning the entire slide to ensure that small pockets of amplified cells are not missed. Ideally, two or more representative fields should be selected and at least 20 randomly selected cells scored within each area, but this might not be feasible in the case of core biopsies containing a small amount of tumor. If there is evidence of heterogeneity, assessment of additional cells and/or fields may be 
useful, and at least 60 cells should be counted if there are scattered nuclei with HER2 amplification. Specifically, additional blocks of the tumor and of lymph-node metastases (if present) should be tested to avoid missing an area of frank HER2 amplification. We also note the value of bright-field ISH techniques (ie, CISH, SISH, BDISH, and DDISH) in assessment of genetic heterogeneity, as these assays permit evaluation of the entire slide under light microscopy. ${ }^{72}$ Improved FISH techniques ${ }^{87}$ may also reduce the risk of overlooking focal amplified cells due to signal quality and increased DAPI counterstain. In addition, staining of slides can be carried out within 4 hours (J Rüschoff, in preparation). As IHC can also assist in identifying target cells for ISH assessment, a newly developed combined gene-protein assay may be a valuable tool in these cases. ${ }^{88}$

Finally, we highlight the need for outcomes data addressing whether genetically heterogeneous tumors with HER2-amplified subclones respond to trastuzumab. Analysis of archival tissue samples from trastuzumab clinical trials may help answer this question and determine whether eligibility criteria can be expanded to include patients with genetically heterogeneous tumors not currently regarded as HER2 + . At present, there is no indication for trastuzumab in patients with 1-10\% amplified cells. For these patients, we recommend repeating the assay on different tumor blocks or lymph-node metastases. If the percentage remains in the $1-10 \%$ range, the case should be considered negative and the proportion of amplified cells should be included in the pathology report, as these patients are most likely to benefit from subsequent re-testing of distant metastases.

\section{Conclusions}

Apparent polysomy of chromosome 17 and genetic heterogeneity of HER2 present major diagnostic challenges when evaluating HER2 status. In this review, we have made several recommendations based on the literature review and the clinical experience of the authors to assist HER2 status determination in such complex cases (summarized in Figures 1 and 2, and Table 4). It is our hope that

Table 4 Authors' consensus recommendations

- Increases in CEP17 copy number observed by ISH should not be interpreted to indicate polysomy of chromosome 17.

- If there is evidence of centromeric abnormalities, absolute HER2 copy number (mean $\geq 6$ copies) is preferable to HER2:CEP17 ratio for defining HER2 status.

- HER2 + status should be assigned if any one or more of the following applies: IHC $3+$; HER2:CEP17 ratio $\geq 2$; or mean HER2 copy number $\geq 6$.

o IHC 3 + tumors should be considered HER2 + (taking into account well-controlled methods for assessment) irrespective of the FISH result or polysomy 17.

o When the mean HER2 copy number is $\geq 6$ and the IHC score is $2+$, tumors should be assessed as HER $2+$, irrespective of HER2:CEP17 ratio.

- Confirmatory IHC testing, use of additional chromosome 17 ISH probes (eg, SMS, RARA), or molecular karyotyping may assist determination of HER2 status in complex cases.

- Future studies should utilize aCGH or other pangenomic techniques to further evaluate the clinical significance of abnormal chromosome 17 status, including polysomy.
To ensure consistency with the Food and Drug Administration cutoff of $10 \%$ for IHC-assessed HER2 status, tumors with $>10 \%$ HER2-amplified cells should be considered HER2 + .

- To avoid missing areas of genetic heterogeneity, it is essential that the entire slide be scanned before selecting areas for analysis.

- Sufficient representative fields should be analyzed (20 randomly selected cells within each area), with scoring of additional fields and/or cells if there is evidence of heterogeneity. Specifically, additional blocks of the tumor and of lymph-node metastases (if present) should be tested to avoid missing an area of frank HER2 amplification.

- Bright-field ISH techniques (ie, CISH, SISH, BDISH, and DDISH) permit evaluation of the entire slide under light microscopy and so may facilitate evaluation of heterogeneous cases. IHC can also assist identification of target cells for ISH assessment.

- If a tumor exhibits a cohesive clone of amplified cells, the tumor should be classified as amplified and the amplified clone scored separately from the rest of the tumor. If there are scattered, single amplified cells throughout the tumor, the average HER2:CEP17 score from at least 60 cells (minimum) should be used to classify the case as amplified or nonamplified.

- For patients with 1-10\% HER2-amplified cells, ISH should be repeated on different tumor blocks or on nodal metastases, if available. If the percentage remains in the 1-10\% range, the case should be considered negative and the proportion of amplified cells should be included in the pathology report, as these patients are most likely to benefit from subsequent re-testing of metastases.

- Future studies should evaluate the potential for trastuzumab response in tumors with HER2-amplified subclones not meeting the current criteria for HER2-positivity.

Abbreviations: aCGH, array-comparative genomic hybridization; BDISH, bright-field double in situ hybridization; CEP17, chromosome enumeration probe 17; CISH, chromogenic in situ hybridization; DDISH, dual-hapten, dual-color in situ hybridization; HER2, human epidermal growth factor receptor 2; IHC, immunohistochemistry; ISH, in situ hybridization; FISH, fluorescence in situ hybridization; SISH, silver in situ hybridization. 
these issues will be further addressed in the next evolution of HER2 testing guidelines to help optimize care for patients with HER2 + breast cancer.

\section{Acknowledgements}

Support for third-party writing assistance for this manuscript was provided by F Hoffmann-La Roche Ltd, Canada.

\section{Disclosure/conflict of interest}

All authors have participated in Advisory Boards and received honoraria from $\mathrm{F}$ Hoffman-La Roche. MV has also received research funding and lecture fees from F Hoffman-La Roche. GV has acted as a consultant for Dako. FP MD has acted as a consultant for GSK.

\section{References}

1 Popescu NC, King CR, Kraus MH. Localization of the human erbB-2 gene on normal and rearranged chromosomes 17 to bands q12-21.32. Genomics 1989;4: 362-366.

2 Wolff AC, Hammond ME, Schwartz JN, et al. American Society of Clinical Oncology/College of American Pathologists guideline recommendations for human epidermal growth factor receptor 2 testing in breast cancer. J Clin Oncol 2007;25:118-145.

3 Slamon DJ, Clark GM, Wong SG, et al. Human breast cancer: correlation of relapse and survival with amplification of the HER-2/neu oncogene. Science 1987;235:177-182.

4 Press MF, Bernstein L, Thomas PA, et al. HER-2/neu gene amplification characterized by fluorescence in situ hybridization: poor prognosis in node-negative breast carcinomas. J Clin Oncol 1997;15:2894-2904.

5 Kallioniemi OP, Holli K, Visakorpi T, et al. Association of c-erbB-2 protein over-expression with high rate of cell proliferation, increased risk of visceral metastasis and poor long-term survival in breast cancer. Int J Cancer 1991;49:650-655.

6 Vogel CL, Cobleigh MA, Tripathy D, et al. Efficacy and safety of trastuzumab as a single agent in first-line treatment of HER2-overexpressing metastatic breast cancer. J Clin Oncol 2002;20:719-726.

7 Marty M, Cognetti F, Maraninchi D, et al. Randomized phase II trial of the efficacy and safety of trastuzumab combined with docetaxel in patients with human epidermal growth factor receptor 2-positive metastatic breast cancer administered as first-line treatment: the M77001 study group. J Clin Oncol 2005;23:4265-4274.

8 Joensuu H, Kellokumpu-Lehtinen PL, Bono $\mathrm{P}$, et al. Adjuvant docetaxel or vinorelbine with or without trastuzumab for breast cancer. $\mathrm{N}$ Engl J Med 2006;354:809-820.

9 Piccart-Gebhart MJ, Procter M, Leyland-Jones B, et al. Trastuzumab after adjuvant chemotherapy in HER2positive breast cancer. N Engl J Med 2005;353: 1659-1672.
10 Romond EH, Perez EA, Bryant J, et al. Trastuzumab plus adjuvant chemotherapy for operable HER2positive breast cancer. $N$ Engl J Med 2005;353: 1673-1684.

11 Slamon DJ, Leyland-Jones B, Shak S, et al. Use of chemotherapy plus a monoclonal antibody against HER2 for metastatic breast cancer that overexpresses HER2. N Engl J Med 2001;344:783-792.

12 Smith I, Procter M, Gelber RD, et al. 2-Year follow-up of trastuzumab after adjuvant chemotherapy in HER2-positive breast cancer: a randomised controlled trial. Lancet 2007;369:29-36.

13 Boekhout AH, Beijnen JH, Schellens JH. Trastuzumab. Oncologist 2011;16:800-810.

14 Banerjee S, Smith IE. Management of small HER2positive breast cancers. Lancet Oncol 2010;11: 1193-1199.

15 Jackisch C. HER-2-positive metastatic breast cancer: optimizing trastuzumab-based therapy. Oncologist 2006;11(Suppl 1):34-41.

16 NCCN Clinical Practice Guidelines in Oncology: Breast Cancer, Vol 3, 2012, pp 1-176.

17 Tse CH, Hwang HC, Goldstein LC, et al. Determining true HER2 gene status in breast cancers with polysomy by using alternative chromosome 17 reference genes: implications for anti-HER2 targeted therapy. J Clin Oncol 2011;29:4168-4174.

18 Hammond ME, Hayes DF, Wolff AC. Clinical Notice for American Society of Clinical Oncology-College of American Pathologists guideline recommendations on ER/PgR and HER2 testing in breast cancer. J Clin Oncol 2011;29:e458.

19 Sauter G, Lee J, Bartlett JM, et al. Guidelines for human epidermal growth factor receptor 2 testing: biologic and methodologic considerations. J Clin Oncol 2009;27:1323-1333.

20 Viale G. Controversies in testing for HER2. ASCO Educ Book 2011;3-7.

21 Albertson DG. Gene amplification in cancer. Trends Genet 2006;22:447-455.

22 Dowsett M, Bartlett J, Ellis IO, et al. Correlation between immunohistochemistry (HercepTest) and fluorescence in situ hybridization (FISH) for HER-2 in 426 breast carcinomas from 37 centres. J Pathol 2003;199:418-423.

23 Reinholz MM, Bruzek AK, Visscher DW, et al. Breast cancer and aneusomy 17: implications for carcinogenesis and therapeutic response. Lancet Oncol 2009;10:267-277.

24 Dal Lago L, Durbecq V, Desmedt C, et al. Correction for chromosome-17 is critical for the determination of true Her-2/neu gene amplification status in breast cancer. Mol Cancer Ther 2006;5:2572-2579.

25 Vranic S, Teruya B, Repertinger S, et al. Assessment of HER2 gene status in breast carcinomas with polysomy of chromosome 17. Cancer 2011;117:48-53.

26 Tubbs RR, Pettay JD, Roche PC, et al. Discrepancies in clinical laboratory testing of eligibility for trastuzumab therapy: apparent immunohistochemical false-positives do not get the message. J Clin Oncol 2001;19: 2714-2721.

27 Schmidt C. How do you tell whether a breast cancer is HER2 positive? Ongoing studies keep debate in high gear. J Natl Cancer Inst 2011;103:87-89.

28 Murthy SS, Sandhya DG, Ahmed F, et al. Assessment of HER2/Neu status by fluorescence in situ hybridization in immunohistochemistry-equivocal cases of invasive 
ductal carcinoma and aberrant signal patterns: a study at a tertiary cancer center. Indian J Pathol Microbiol 2011;54:532-538.

29 Ma Y, Lespagnard L, Durbecq V, et al. Polysomy 17 in HER-2/neu status elaboration in breast cancer: effect on daily practice. Clin Cancer Res 2005;11: 4393-4399.

30 Bose S, Mohammed M, Shintaku P, Rao PN. Her-2/neu gene amplification in low to moderately expressing breast cancers: possible role of chromosome 17/Her-2/ neu polysomy. Breast J 2001;7:337-344.

31 Cuadros M, Cano C, Lopez FJ, et al. HER2 status in breast cancer: experience of a Spanish National Reference Centre. Clin Transl Oncol 2011;13:335-340.

32 Downs-Kelly E, Yoder BJ, Stoler M, et al. The influence of polysomy 17 on HER2 gene and protein expression in adenocarcinoma of the breast: a fluorescent in situ hybridization, immunohistochemical, and isotopic mRNA in situ hybridization study. Am J Surg Pathol 2005;29:1221-1227.

33 Hajduch $\mathrm{M}$, Trojanec $\mathrm{R}$, Bouchalova $\mathrm{K}$, et al. Chromosome 17 polysomy and Her-2/neu status in metastatic breast cancer patients indicated to trastuzumab therapy. J Clin Oncol 2005;23(16 Suppl):abstract 9584.

34 Hofmann M, Stoss O, Gaiser T, et al. Central HER2 IHC and FISH analysis in a trastuzumab (Herceptin) phase II monotherapy study: assessment of test sensitivity and impact of chromosome 17 polysomy. J Clin Pathol 2008;61:89-94.

35 Hyun CL, Lee HE, Kim KS, et al. The effect of chromosome 17 polysomy on HER-2/neu status in breast cancer. J Clin Pathol 2008;61:317-321.

36 Kokate P, Sawaimoon S, Bhatia S, Mandava S. Evaluation of genetic status of HER-2/neu and aneusomy 17 by fluorescence in situ hybridization and comparison with immunohistochemistry assay from Indian breast cancer patients. Genet Test Mol Biomarkers 2012;16:239-245.

37 Krishnamurti U, Hammers JL, Atem FD, et al. Poor prognostic significance of unamplified chromosome 17 polysomy in invasive breast carcinoma. Mod Pathol 2009;22:1044-1048.

38 Merola R, Mottolese M, Orlandi G, et al. Analysis of aneusomy level and HER-2 gene copy number and their effect on amplification rate in breast cancer specimens read as $2+$ in immunohistochemical analysis. Eur J Cancer 2006;42:1501-1506.

39 Mezzelani A, Alasio L, Bartoli C, et al. c-erbB2/neu gene and chromosome 17 analysis in breast cancer by FISH on archival cytological fine-needle aspirates. $\mathrm{Br} \mathrm{J}$ Cancer 1999;80:519-525.

40 Öhlschlegel C, Zahel K, Kradolfer D, et al. HER2 genetic heterogeneity in breast carcinoma. J Clin Pathol 2011;64:1112-1116.

41 Salido M, Tusquets I, Corominas JM, et al. Polysomy of chromosome 17 in breast cancer tumors showing an overexpression of ERBB2: a study of 175 cases using fluorescence in situ hybridization and immunohistochemistry. Breast Cancer Res 2005;7:R267-R273.

42 Takehisa M, Sasa M, Bando Y, et al. Chromosomal aneusomy (chr 1, 11, 17) detected by fluorescence in situ hybridization may be a prognostic factor in breast cancer. Anticancer Res 2007;27:1073-1078.

43 Torrisi R, Rotmensz N, Bagnardi V, et al. HER2 status in early breast cancer: relevance of cell staining patterns, gene amplification and polysomy 17. Eur J Cancer 2007;43:2339-2344.
44 Tsukamoto F, Miyoshi Y, Egawa C, et al. Clinicopathologic analysis of breast carcinoma with chromosomal aneusomy detected by fluorescence in situ hybridization. Cancer 2001;93:165-170.

45 Tubbs RR, Hicks DG, Cook J, et al. Fluorescence in situ hybridization (FISH) as primary methodology for the assessment of HER2 status in adenocarcinoma of the breast: a single institution experience. Diagn $\mathrm{Mol}$ Pathol 2007;16:207-210.

46 Vanden Bempt I, Van LP, Drijkoningen $\mathrm{M}$, et al. Polysomy 17 in breast cancer: clinicopathologic significance and impact on HER-2 testing. J Clin Oncol 2008;26:4869-4874.

47 Varshney D, Zhou YY, Geller SA, Alsabeh R. Determination of HER-2 status and chromosome 17 polysomy in breast carcinomas comparing HercepTest and PathVysion FISH assay. Am J Clin Pathol 2004;121:70-77.

48 Wang S, Hossein SM, Frenkel EP, et al. Aneusomy 17 in breast cancer: its role in HER-2/neu protein expression and implication for clinical assessment of HER-2/neu status. Mod Pathol 2002;15:137-145.

49 Watters AD, Going JJ, Cooke TG, Bartlett JM. Chromosome 17 aneusomy is associated with poor prognostic factors in invasive breast carcinoma. Breast Cancer Res Treat 2003;77:109-114.

50 Zaczek A, Markiewicz A, Supernat A, et al. Prognostic value of TOP2A gene amplification and chromosome 17 polysomy in early breast cancer. Pathol Oncol Res 2012;18:885-894.

51 Zhu X, Lu Y, Lu H, et al. Genetic alterations and protein expression of HER2 and chromosome 17 polysomy in breast cancer. Hum Pathol 2011;42: 1499-1504.

52 Petroni S, Addati T, Mattioli E, et al. Centromere 17 copy number alteration: negative prognostic factor in invasive breast cancer? Arch Pathol Lab Med 2012;136:993-1000.

53 Lal P, Salazar PA, Ladanyi M, et al. Impact of polysomy 17 on HER-2/neu immunohistochemistry in breast carcinomas without HER-2/neu gene amplification. J Mol Diagn 2003;5:155-159.

54 Sahoo R, Babu VC, Harini VV, et al. Her-2/neu overexpression due to polysomy 17 in breast cancer: molecular testing to guide therapeutic options. Onkologie 2011;34:356-360.

55 Kaufman PA, Broadwater G, Lezon-Geyda LG. CALGB 150002: correlation of HER2 and chromosome 17 (ch17) copy number with trastuzumab (T) efficacy in CALGB 9840, paclitaxel (P) with or without $\mathrm{T}$ in HER2 + and HER2- metastatic breast cancer (MBC). J Clin Oncol 2007;25(18 Suppl):abstract 1009.

56 Seidman AD, Berry D, Cirrincione C, et al. Randomized phase III trial of weekly compared with every-3weeks paclitaxel for metastatic breast cancer, with trastuzumab for all HER-2 overexpressors and random assignment to trastuzumab or not in HER-2 nonoverexpressors: final results of Cancer and Leukemia Group B protocol 9840. J Clin Oncol 2008;26: 1642-1649.

57 Downey L, Livingston RB, Koehler M, et al. Chromosome 17 polysomy without human epidermal growth factor receptor 2 amplification does not predict response to lapatinib plus paclitaxel compared with paclitaxel in metastatic breast cancer. Clin Cancer Res 2010;16: 1281-1288. 
58 Dowsett M, Procter M, McCaskill-Stevens W, et al. Disease-free survival according to degree of HER2 amplification for patients treated with adjuvant chemotherapy with or without 1 year of trastuzumab: the HERA Trial. J Clin Oncol 2009;27:2962-2969.

59 Orlando L, Del CB, Gandini S, et al. Topoisomerase IIalpha gene status and prediction of pathological complete remission after anthracycline-based neoadjuvant chemotherapy in endocrine non-responsive Her2/neu-positive breast cancer. Breast 2008;17: 506-511.

60 Moelans CB, de Weger RA, van Diest PJ. Absence of chromosome 17 polysomy in breast cancer: analysis by CEP17 chromogenic in situ hybridization and multiplex ligation-dependent probe amplification. Breast Cancer Res Treat 2010;120:1-7.

61 Troxell ML, Bangs CD, Lawce HJ, et al. Evaluation of Her-2/neu status in carcinomas with amplified chromosome 17 centromere locus. Am J Clin Pathol 2006;126:709-716.

62 Marchiò C, Lambros MB, Gugliotta P, et al. Does chromosome 17 centromere copy number predict polysomy in breast cancer? A fluorescence in situ hybridization and microarray-based CGH analysis. J Pathol 2009;219:16-24.

63 Yeh IT, Martin MA, Robetorye RS, et al. Clinical validation of an array CGH test for HER2 status in breast cancer reveals that polysomy 17 is a rare event. Mod Pathol 2009;22:1169-1175.

64 Viale G. Be precise! The need to consider the mechanisms for CEP17 copy number changes in breast cancer. J Pathol 2009;219:1-2.

65 Moelans CB, Reis-Filho JS, van Diest PJ. Implications of rarity of chromosome 17 polysomy in breast cancer. Lancet Oncol 2011;12:1087-1089.

66 Zabaglo L, Stoss O, Rueschoff J, et al. Impact of HER2 staining intensity on prognosis and treatment benefit of adjuvant trastuzumab given after chemotherapy: the HERA Trial Experience. Cancer Res 2010;70 (24 Suppl):abstract PD10-01.

67 Dekker TJ, Borg ST, Hooijer GK, et al. Determining sensitivity and specificity of HER2 testing in breast cancer using a tissue micro-array approach. Breast Cancer Res 2012;14:R93.

68 Bartlett JM, Campbell FM, Mallon EA. Determination of HER2 amplification by in situ hybridization: when should chromosome 17 also be determined? Am J Clin Pathol 2008;130:920-926.

69 Egervari K, Kosa C, Szollosi Z. Impact of chromosome 17 centromere region assessment on HER2 status reported in breast cancer. Pathol Res Pract 2011;207: $468-471$.

70 Gunn S, Yeh IT, Lytvak I, et al. Clinical array-based karyotyping of breast cancer with equivocal HER2 status resolves gene copy number and reveals chromosome 17 complexity. BMC Cancer 2010;10:396.

71 Gerlinger M, Rowan AJ, Horswell S, et al. Intratumor heterogeneity and branched evolution revealed by multiregion sequencing. $N$ Engl J Med 2012;366: 883-892.

72 Hanna W, Nofech-Mozes S, Kahn HJ. Intratumoral heterogeneity of HER2/neu in breast cancer-a rare event. Breast J 2007;13:122-129.

73 Bernasconi B, Chiaravalli AM, Finzi G, et al. Genetic heterogeneity in HER2 testing may influence therapy eligibility. Breast Cancer Res Treat 2012;133: 161-168.
74 Vance GH, Barry TS, Bloom KJ, et al. Genetic heterogeneity in HER2 testing in breast cancer: panel summary and guidelines. Arch Pathol Lab Med 2009;133:611-612.

75 Brunelli M, Manfrin E, Martignoni G, et al. Genotypic intratumoral heterogeneity in breast carcinoma with HER2/neu amplification: evaluation according to ASCO/CAP criteria. Am J Clin Pathol 2009;131:678-682.

76 Lewis JT, Ketterling RP, Halling KC, et al. Analysis of intratumoral heterogeneity and amplification status in breast carcinomas with equivocal $(2+)$ HER-2 immunostaining. Am J Clin Pathol 2005;124:273-281.

77 Albarracin C, Edgerton ME, Gilcrease MZ, et al. Is it too soon to start reporting HER2 genetic heterogeneity? Arch Pathol Lab Med 2010;134:162-163.

78 Hsu CY, Li AF, Yang CF, Ho DM. Proposal of modification for the definition of genetic heterogeneity in HER2 testing in breast cancer. Arch Pathol Lab Med 2010;134:162.

79 Chang MC, Malowany JI, Mazurkiewicz J, et al. 'Genetic heterogeneity' in HER2/neu testing by fluorescence in situ hybridization: a study of 2,522 cases. Mod Pathol 2012;25:683-688.

80 Bartlett JM, Starczynski J, Atkey N, et al. HER2 testing in the UK: recommendations for breast and gastric in-situ hybridisation methods. J Clin Pathol 2011;64: 649-653.

81 Starczynski J, Atkey N, Connelly Y, et al. HER2 gene amplification in breast cancer: a rogues' gallery of challenging diagnostic cases: UKNEQAS interpretation guidelines and research recommendations. Am J Clin Pathol 2012;137:595-605.

82 Allison KH, Dintzis SM, Schmidt RA. Frequency of HER2 heterogeneity by fluorescence in situ hybridization according to CAP expert panel recommendations: time for a new look at how to report heterogeneity. Am J Clin Pathol 2011;136:864-871.

83 Bartlett AI, Starcyznski J, Robson T, et al. Heterogeneous HER2 gene amplification: impact on patient outcome and a clinically relevant definition. Am J Clin Pathol 2011;136:266-274.

84 Seol H, Lee HJ, Choi Y, et al. Intratumoral heterogeneity of HER2 gene amplification in breast cancer: its clinicopathological significance. Mod Pathol 2012;25: 938-948.

85 Perez EA, Dueck AC, McCullough AE, et al. Predictability of adjuvant trastuzumab benefit in N9831 patients using the ASCO/CAP HER2-positivity criteria. J Natl Cancer Inst 2012;104:159-162.

86 Valent A, Delaloge S, Ferchiou M, et al. Genetic heterogeneity of amplification status in breast invasive carcinoma with $2+$ HER2 immunostaining: What Can We Learn? Cancer Res 2011;71(24 Suppl):abstract P3-05-07.

87 Matthiesen SH, Hansen CM. Fast and non-toxic in situ hybridization without blocking of repetitive sequences. PLoS One 2012;7:e40675.

88 Nitta H, Kelly BD, Padilla M, et al. A gene-protein assay for human epidermal growth factor receptor 2 (HER2): brightfield tricolor visualization of HER2 protein, the HER2 gene, and chromosome 17 centromere (CEN17) in formalinfixed, paraffin-embedded breast cancer tissue sections. Diagn Pathol 2012;7:60.

89 Ross JS, Slodkowska EA, Symmans WF, et al. The HER-2 receptor and breast cancer: ten years of targeted anti-HER-2 therapy and personalized medicine. Oncologist 2009;14:320-368. 